Article

\title{
Synthesis and Characterization of a Biomimetic Formulation of Clofazimine Hydrochloride Microcrystals for Parenteral Administration
}

\author{
Mikhail D. Murashov ${ }^{1, * \mathbb{C}}$, Jennifer Diaz-Espinosa ${ }^{1}$, Vernon LaLone ${ }^{1}{ }^{\mathbb{D}}$, Joel W. Y. Tan ${ }^{2}$, \\ Raluca Laza ${ }^{1}$, Xueding Wang ${ }^{2,3}$, Kathleen A. Stringer ${ }^{4}(\mathbb{D})$ and Gus R. Rosania ${ }^{1, *(D)}$ \\ 1 Department of Pharmaceutical Sciences, University of Michigan, Ann Arbor, MI 48109, USA; \\ jendiaz@umich.edu (J.D.-E.); laloneve@umich.edu (V.L.); rmlaza@umich.edu (R.L.) \\ 2 Department of Biomedical Engineering, University of Michigan, Ann Arbor, MI 48109, USA; \\ tanjoel@umich.edu (J.W.Y.T.); xdwang@umich.edu (X.W.) \\ 3 Department of Radiology, University of Michigan, Ann Arbor, MI 48109, USA \\ 4 Department of Clinical Pharmacy, University of Michigan, Ann Arbor, MI, 48109, USA; stringek@umich.edu \\ * Correspondence: murashov@umich.edu (M.D.M.); grosania@umich.edu (G.R.R.); \\ Tel.: +1-(734)-763-1032 (G.R.R.)
}

Received: 26 October 2018; Accepted: 14 November 2018; Published: 17 November 2018

check for updates

\begin{abstract}
Clofazimine (CFZ) is a broad spectrum antimycobacterial agent recommended by the World Health Organization as a first line treatment for leprosy and second line treatment for multidrug resistant tuberculosis. Oral administration of CFZ leads to a red skin pigmentation side effect. Since CFZ is a weakly basic, red phenazine dye, the skin pigmentation side effect results from lipophilic partitioning of the circulating, free base (neutral) form of CFZ into the skin. Here, we developed a stable and biocompatible formulation of $\mathrm{CFZ}-\mathrm{HCl}$ microcrystals that mimics the predominant form of the drug that bioaccumulates in macrophages, following long term oral CFZ administration. In mice, intravenous injection of these biomimetic CFZ-HCl microcrystals led to visible drug accumulation in macrophages of the reticuloendothelial system with minimal skin accumulation or pigmentation. In fact, no skin pigmentation was observed when the total amount of $\mathrm{CFZ}-\mathrm{HCl}$ administered was equivalent to the total oral dose leading to maximal skin pigmentation. Thus, parenteral (injected or inhaled) biomimetic formulations of CFZ-HCl could be instrumental to avoid the pigmentation side effect of oral CFZ therapy.
\end{abstract}

Keywords: crystal-like drug inclusion (CLDI); micronized crystals; jet milling/micronization; drug repurposing; CFZ-induced skin pigmentation; adverse drug reaction (ADR); macrophages

\section{Introduction}

Clofazimine (CFZ) is a weakly basic, red-pigmented, FDA-approved, phenazine antibiotic that is included in the World Health Organization's (WHO) List of Essential Medications as part of the antibiotic cocktail used for the standard treatment for leprosy [1-5]. It has been in clinical use since the 1960s and has contributed to the cure of more than 16 million people worldwide [1-5]. Due to its potent activity against Mycobacterium tuberculosis, the WHO now recommends CFZ as a second line agent against multi-drug resistant tuberculosis (MDR-TB) [3,6-10]. In humans, CFZ exhibits atypical pharmacokinetic properties [11,12]. In mice, following long-term (i.e., weeks) oral administration, solid drug precipitates accumulate in tissue macrophages, forming red crystal-like drug inclusions (CLDIs) that are most abundant in the liver and spleen [13-15]. This phenomenon has also been reported in humans treated with CFZ [11,12]. Interestingly, these biocrystals display robust stability inside macrophages and remain in the body long after discontinuation of treatment (>8 weeks) [13]. 
The preliminary analysis of isolated CLDIs from spleen and liver of CFZ treated mice revealed that CLDIs contained a hydrochloride salt form of the drug, which is stabilized by the acidic and high chloride concentrations present in macrophage lysosomes, while the orally-administered form of the drug is the free base [16].

In terms of its toxicological properties, the major side effect of orally administered CFZ is a strong red skin pigmentation, observed in more than $94 \%$ of patients $[17,18]$. CFZ-induced skin pigmentation is attributed to the circulating, soluble free base form of CFZ that partitions into the subcutaneous fat layer of the skin rather than CLDI formation and accumulation [19]. Even though prolonged CFZ treatment is associated with massive drug biocrystal accumulation within resident tissue macrophages, there are no obvious toxicological manifestations from these biocrystals. Instead, CLDIs are biocompatible, stable, long-lived, and relatively non-toxic $[3,20]$. Phagocytosed CLDIs modulate innate immune signaling by dampening pro-inflammatory and enhancing anti-inflammatory pathways via inhibition of tumor necrosis factor alpha (TNF $\alpha$ ) and enhancement of interleukin 1 receptor antagonist (IL-1RA) secretion [3,20]. Specifically, CFZ inhibited carrageenan- and lipopolysaccharide-induced inflammation in the footpads and lungs, respectively, in 8-week-CFZ-treated mice, in an IL-1RA-dependent manner [3].

Since the skin pigmentation side effect is likely due to the free base form of the drug that partitions from the blood to the skin following oral administration, we decided to test whether parenteral administration of CFZ-HCl microcrystals could be used to avoid the drug's skin pigmentation side effect. We hypothesized that the injected, micronized CFZ-HCl particles would be ingested by macrophages and stabilized by the phagolysosomal microenvironment. In order to test this hypothesis, we developed and tested CFZ-HCl particles side-by-side with CLDIs and other solid forms of CFZ, in terms of their physicochemical characteristics. Furthermore, biological experiments were conducted to test the performance of biomimetic $\mathrm{CFZ}-\mathrm{HCl}$ formulations following phagocytosis by macrophages in vitro, and in vivo after administering the drug via intravenous (IV) tail-vein bolus injection. The results indicate that a biomimetic formulation of CFZ-HCl can be effectively synthesized and delivered parenterally to circumvent the CFZ-induced skin pigmentation side effect.

\section{Materials and Methods}

\subsection{Synthesis of Different Clofazimine (CFZ) Solids}

Different CFZ salt crystals were synthesized by adding $1 \mathrm{M}$ of ammonium salts in MiliQ water to 2 mM CFZ (C8895, Sigma-Aldrich, St. Louis, MO, USA) in methanol in a 1:1 ratio $(v / v)$. Ammonium bromide, carbonate, citrate dibasic, nitrate, phosphate dibasic, and sulfate were all purchased from Sigma-Aldrich (213349; 207861; 25102; 221244; 215996; A4418 (respectively); Sigma-Aldrich, St. Louis, MO, USA). Ammonium acetate and chloride were purchased from Fisher Scientific (A639; A661 (respectively); Fisher Scientific, Fair Lawn, NJ, USA). Ammonium iodide was purchased from Acros Organics (448071000, Acros Organics, Morris Plains, NJ, USA).

\subsection{Isolation of Crystal-Like Drug Inclusions (CLDIs)}

CLDI purification and isolation were performed as previously described with minor modifications [13,14,21]. In brief, liver and spleen from mice that were fed CFZ for 8 weeks from previous experiments were homogenized by cutting the organs into smaller pieces and utilizing mechanical homogenizer (Pro200; Pro Scientific, Oxford, CT, USA). Liver and spleen homogenates were filtered through a $100 \mu \mathrm{m}$ strainer, and the filtrate was collected in a $50 \mathrm{~mL}$ centrifuge tube and diluted up to $50 \mathrm{~mL}$ with $1 \times$ Phosphate Buffered Saline (PBS) (10010023, Gibco, Life Technologies, Carlsbad, CA, USA). The filtrate was then centrifuged at $250 \times g$ for $6 \mathrm{~min}$. The supernatant was discarded, and fresh PBS was added up to $50 \mathrm{~mL}$. This step was repeated twice, and after the final washing step, the red-CLDI containing pellet was resuspended in $2-5 \mathrm{~mL}$ of $10 \%$ sucrose. From the pellet, CLDIs were further purified using a three-layer discontinuous gradient $(50 \%, 30 \%$, and 
$10 \%$ sucrose in PBS) centrifugation method $(3200 \times g, 60 \mathrm{~min})$. After centrifugation, the top layers were discarded, and the CLDIs pellet was resuspended in PBS and snap frozen in liquid nitrogen in preparation for future analysis.

\subsection{Bulk Synthesis of CFZ-HCl Salt Crystals}

CFZ free base (10 g; Sigma-Aldrich, St. Louis, MO, USA) was placed in $2 \mathrm{~L}$ of $1 \mathrm{M} \mathrm{HCl}$ in an Erlenmeyer flask with a magnetic stir bar. After the addition of CFZ, the reaction was sealed with parafilm and stirred in the dark for $72 \mathrm{~h}$. After $72 \mathrm{~h}$, the stirring was turned off and CFZ salt crystals were allowed to precipitate. Following crystal precipitation, the $\mathrm{HCl}$ reactant was decanted and discarded. The residual acid containing the CFZ salt crystals was centrifuged $\left(2000 \times g, 10 \mathrm{~min}, 4{ }^{\circ} \mathrm{C}\right)$, the supernatant was discarded, and the pellet was washed thrice with declining concentrations of $\mathrm{HCl}$ $(100 \mathrm{mM}, 10 \mathrm{mM}$, and $1 \mathrm{mM}$ ) to reduce the amount of chloride present in the solution. In between washing steps, samples were centrifuged $\left(2000 \times g, 10 \mathrm{~min}, 4^{\circ} \mathrm{C}\right)$. After the last wash, crystals were resuspended in MiliQ water and immediately snap frozen in liquid nitrogen and then freeze-dried.

\subsection{Micronization (Jet Milling) and Sterilization}

A SepSol, Sturtevant Inc. (Separation Solutions; SepSol Process Solutions, Kalamazoo, MI, USA) air jet mill was used to micronize the bulk synthesized CFZ-HCl crystals and CFZ free base crystals (control) to a particle size distribution within the desired range $(0.5-5 \mu \mathrm{m})$. Following the company's specifications, the air jet mill was set at 50 psi grind pressure and 100 psi feed pressure. Filtered, dried, compressed air was used as the air source for the mill. Altogether, four batches of CFZ-HCl microcrystals (net weight $\sim 40 \mathrm{~g}$ ) and three batches of CFZ free base microcrystals (net weight $\sim 20 \mathrm{~g}$ ) were produced with $\sim 80-90 \%$ yield from milling. Both types of micronized CFZ crystals were stored at $-20^{\circ} \mathrm{C}$ until the time of experimentation. Before each experiment, CFZ microcrystals were sterilized by dry heat at $170{ }^{\circ} \mathrm{C}$ for $1.5 \mathrm{~h}$, using a bench top vacuum oven at 5 psi (Model 5831; National Appliance Co., Portland, OR, USA).

\subsection{Particle Size Determination}

The CFZ microcrystals particle size after synthesis and after micronization were analyzed using Zeta-Sizer (Malvern Instruments, Nano-ZS90, Malvern, UK) and brightfield microscopy using Nikon Eclipse Ti inverted microscope (Nikon Instruments, Melville, NY, USA).

\subsection{Proton Nuclear Magnetic Resonance Spectroscopy Analysis}

Proton $\left({ }^{1} \mathrm{H}\right)$ nuclear magnetic resonance (NMR) spectroscopy was performed as previously described [16]. Briefly, one-dimensional ${ }^{1} \mathrm{H}-\mathrm{NMR}$ spectra of micronized CFZ-HCl crystals at different stages of manufacturing were acquired using an $11.74 \mathrm{~T}(500 \mathrm{MHz}) \mathrm{NMR}$ spectrometer with a VNMRS console and a 7510-AS autosampler system operated by host software VNMRJ 3.2 and equipped with a $5 \mathrm{~mm}$ Agilent One NMR probe with Z-axis gradients. The samples were dissolved in dimethyl sulfoxide-D6 (D, 99.9\%) (DMSO- $d_{6}$; Cambridge Isotope Laboratories, Inc., Andover, MA, USA). The NMR data were acquired at room temperature and processed using MestreNova 9.0 software (MestreLab, Santiago de Compostela, Spain).

\subsection{Powder X-ray Diffraction Analysis}

Powder X-ray diffraction ( $\mathrm{pXRD}$ ) spectra of micronized CFZ-HCl crystals at different stages of manufacturing were taken by Rigaku Miniflex X-ray diffractometer (Rigaku-USA Inc., Danvers, MA, USA) using $\mathrm{Cu} \mathrm{K} \alpha$ radiation, a tube voltage of $30 \mathrm{kV}$, and a tube current of $15 \mathrm{~mA}$. Measurements were taken from $5^{\circ}$ to $40^{\circ}$ at a continuous scan rate of $2.5^{\circ} / \mathrm{min}$. 


\subsection{Raman Microscopy}

Raman spectra were acquired with a WiTec alpha300R confocal Raman microscope (WiTec, Ulm, Germany) equipped with a $532 \mathrm{~nm}$ solid-state sapphire excitation laser and charge coupled device (CCD) detector. For single point spectra, the laser was focused on the sample acquiring each Raman spectrum with an integration time of $75 \mathrm{~s}$, using Zeiss EC EPIPLAN 50X objective (N.A. = 0.75). Alternatively, for large area scans, the laser rastered across a $100 \mu \mathrm{m}$ by $100 \mu \mathrm{m}$ area of the sample with a step size of $10 \mu \mathrm{m}$ and an integration time of $2 \mathrm{~s}$ per pixel, using Zeiss $10 \mathrm{X}$ objective. To measure quality and stability of individual CFZ microcrystals, single point spectra were taken from individual particles for micronized CFZ-HCl, micronized CFZ-HCl in diluent, and micronized CFZ free base that were dispersed on mica chips. Cosmic rays were removed from all spectra using the WiTec Project FOUR software. A MATLAB ${ }^{\circledR}$ processing algorithm developed in-house [22] was used to baseline-subtract, normalize, and overlay spectra to qualitatively identify the collected micronized sample spectra by comparing them to both $\mathrm{CFZ}-\mathrm{HCl}$ and $\mathrm{CFZ}$ free base reference spectra.

\subsection{Brightfield and Fluorescence Microscopy}

Microscopy was performed using a Nikon Eclipse Ti inverted microscope (Nikon Instruments, Melville, NY, USA) as previously described [19,23]. Briefly, brightfield images were captured using the Nikon DS-3 camera (Nikon Instruments, Melville, NY, USA), and fluorescence imaging in FITC channel (490/510 nm, green) and Cy5 channel (640/670 nm, far-red) was performed with the Photometrics Coolsnap MYO camera system (Photometrics, Tuscon, AZ, USA) under the control of Nikon NIS-Elements AR software (Nikon Instruments, Melville, NY, USA). Illumination for fluorescence imaging was provided by the X-Cite 120Q Widefield Fluorescence Microscope Excitation Light Source (Excelitas Technology, Waltham, MA, USA).

\subsection{Assaying Stability of CFZ-HCl in Aqueous Buffers}

The stability of CFZ-HCl microcrystals was evaluated in IV diluent, synthetic lysosomal buffer [19], and PBS. A small amount of CFZ- $\mathrm{HCl}$ crystals $(<1 \mathrm{mg})$ was placed in a large volume of test media $(\sim 20 \mathrm{~mL})$ and gently stirred for $24 \mathrm{~h}$ to make sure that the equilibrium between the microcrystals and the test medium was reached. After $24 \mathrm{~h}$, the small drop of test media with microcrystals was placed on the glass microscope slide, and the stability of CFZ-HCl microscrystals was evaluated using brightfield and fluorescence microscopy (see Section 2.9).

The diluent for the IV injectable formulation was made using polysorbate 80 (59924 Sigma-Aldrich, St. Louis, MO, USA), sodium chloride (BP358, Fisher Scientific, Fair Lawn, NJ, USA), and Milli-Q water. To coat, disperse, and adjust the size of the lipophilic CFZ-HCl microcrystals, the varying concentrations of polysorbate $80(0-0.5 \%)$ was used [24]. Sodium chloride was added to maintain isotonicity. The $\mathrm{pH}$ was adjusted to $\mathrm{pH} 5$ using $0.01 \mathrm{M} \mathrm{HCl}$ or $0.01 \mathrm{M} \mathrm{NaOH}$ to ensure the stability of $\mathrm{CFZ}-\mathrm{HCl}$ microcrystals in the formulation. For experiments, the diluent was sterilized by sterile filtration with a syringe filter (09-719A; $0.22 \mu \mathrm{m}, \mathrm{MCE}$, Sterile; Fisher Scientific, Fair Lawn, NJ, USA).

The synthetic lysosomal buffer was prepared as previously reported [19]. In brief, synthetic lysosomal buffer was made by preparing $10 \mathrm{mM}$ sodium acetate buffer $(\mathrm{pH} 4.5)$ with $10 \mathrm{mM}$ cetrimonium bromide (CTAB) and $100 \mathrm{mM} \mathrm{NaCl}$ to mimic lysosomal conditions [19].

\subsection{Cell-Based Stability Assays}

The stability of CFZ-HCl microcrystals was evaluated following phagocytosis, using the RAW 264.7 murine macrophage cell line. The cell line was purchased from ATCC (Manassas, VA, USA) and maintained in Dulbecco's modified Eagle medium (DMEM) (11995-065, Gibco, Life Technologies, Carlsbad, CA, USA) supplemented with 10\% fetal bovine serum (FBS) (16000-044, Gibco, Life Technologies, Carlsbad, CA, USA) and 0.1\% penicillin/streptomycin (15140-122, Gibco, Life Technologies, Carlsbad, CA, USA). Cells were maintained at $5 \% \mathrm{CO}_{2}$ at $37{ }^{\circ} \mathrm{C}$ and passaged at 
$80 \%$ confluency. For the assay, the cells were seeded at $5 \times 10^{4}$ cells /well in 6-well plates and were allowed to grow for $24 \mathrm{~h}$, at which point, isolated CLDIs, CFZ-HCl microcrystals, and CFZ free base microcrystals were added at $20 \mu \mathrm{g} / \mathrm{mL}$ in DMEM with $5 \%$ FBS to designated drug treatment plates. The same volume of DMEM with 5\% FBS without drug treatment was added to wells of negative control plates. The cells were treated for $1 \mathrm{~h}$, at which point, the media was removed, and the cells were thoroughly washed twice. DMEM with $10 \%$ FBS and $0.1 \%$ penicillin/streptomycin was then added back into the wells $\left(t_{0}\right)$. Over the next $48 \mathrm{~h}\left(t_{8 \mathrm{~h}}, t_{24 \mathrm{~h}}, t_{48 \mathrm{~h}}\right)$, total cell viability was assessed using trypan blue (0.4\%) exclusion (15250-061, Gibco, Life Technologies, Carlsbad, CA, USA). At every time point, brightfield and fluorescence images were taken, and the viability measurements were calculated in triplicate (\# cells $>100$ per measurement).

\subsection{Animal Studies}

Animal care was provided by the University of Michigan's Unit for Laboratory Animal Medicine (ULAM), and the experimental protocol was submitted to and approved by the University of Michigan's Institutional Committee on Use and Care of Animals (PRO00007593; 5 May 2017).

In order to assess of the skin pigmentation induced by micronized CFZ- $\mathrm{HCl}$ crystals following injection into the systemic circulation, 14 male mice (10-19 weeks old, C57BL6, Jackson Laboratory, Bar Harbor, ME, USA) were assigned to one of 3 groups: CFZ orally fed (OF) group $(n=5), \mathrm{CFZ}-\mathrm{HCl}$ IV injected group $(n=5)$, and the control group $(n=4)$. The CFZ orally fed group and control group mice were fed CFZ or vehicle chow for 9 weeks, respectively, as previously reported $[13,14,20]$. The CFZ-HCl IV injected group received a single IV bolus tail-vein injection with the formulation of CFZ-HCl microcrystals $(200 \mathrm{mg} / \mathrm{kg})$, using a $300 \mu \mathrm{L}$ injection volume, which translates to an approximate total dose of $6 \mathrm{mg}$ of drug microcrystals or 3 weeks of orally administered CFZ (assuming 100\% bioavailability). Animals were sacrificed $24 \mathrm{~h}$ post injection. At the time of sacrifice, mice were euthanized with $\mathrm{CO}_{2}$ inhalation and exsanguination.

\subsubsection{Toxicological Evaluation}

The mice were monitored for behavioral changes and survival (e.g., lethargy, scruffy fur, squinted eyes, etc.) $24 \mathrm{~h}$ post-injection to evaluate the toxicity of the $\mathrm{CFZ}-\mathrm{HCl}$ injections. In addition, plasma samples from the in vivo experiments were assayed for IL-1RA, IL-1 $\beta$, and TNF $\alpha$ by enzyme linked immunosorbent assay (ELISA; Quantikine; R\&D Systems, Minneapolis, MN, USA) in duplicate according to the manufacturer's instructions. The cytokine concentrations were expressed as picograms per milliliter of plasma.

\subsubsection{Immunohistochemistry}

Immunohistochemistry was performed using a previously published protocol with some modifications [25]. In brief, following euthanasia, the liver and spleen were removed en bloc and embedded in Tissue-Plus Optimal Cutting Temperature (OCT) compound (4585, Fisher HealthCare, Houston, TX, USA). Frozen tissue blocks were sectioned ( $6 \mu \mathrm{m}$ thick) using Leica 3050S cryostat, fixed in $4 \%$ paraformaldehyde (15710, Electron Microscopy Sciences, Hatfield, PA, USA) for $10 \mathrm{~min}$, and blocked with $1 \%$ bovine serum albumin (BSA) (810033, MP Biomedicals, Solon, OH, USA), 5\% goat serum (Sigma-Aldrich, St. Louis, MO, USA), and 0.3 M glycine (G8898, Sigma-Aldrich, St. Louis, $\mathrm{MO}, \mathrm{USA}$ ) in PBS for $2 \mathrm{~h}$. The samples were then incubated with primary antibodies, anti-CD68 antibody (ab53444; $1 \mathrm{mg} / \mathrm{mL}$ stock; 1:200 dilution in 1\% BSA; Abcam, Cambridge, UK) or purified rat IgG2a $\mathrm{K}$ isotype control antibody (400502; $0.5 \mathrm{mg} / \mathrm{mL}$ stock; 1:100 dilution in $1 \% \mathrm{BSA}$; Biolegend, San Diego, CA, USA), overnight at $4{ }^{\circ} \mathrm{C}$, followed by incubation with anti-rat $\operatorname{IgG}(\mathrm{H}+\mathrm{L})$ Alexa Fluor ${ }^{\circledR}$ 488 conjugate secondary antibody $(4416 ; 5 \mathrm{mg} / \mathrm{mL}$ stock; 1:500 dilution in 1\% BSA; Cell Signaling Technology, Danvers, MA, USA) for $1 \mathrm{~h}$ at room temperature. Finally, the samples were incubated with Hoechst 33,342 solution (H3570; $1 \mu \mathrm{M}$ stock; 1:10,000 dilution in PBS; Life Technologies, Carlsbad, CA, USA) for $10 \mathrm{~min}$ at room temperature for nuclear detection. After staining was complete, sections were 
mounted with a drop of ProLong ${ }^{\circledR}$ Gold antifade reagent (P36930, Life Technologies, Carlsbad, CA, USA) and sealed with a cover slip. Brightfield and fluorescence images were acquired as previously described in Section 2.9.

\subsubsection{Imaging and Quantification of Skin Pigmentation}

Imaging and quantification of mouse skin samples were performed using the previously published protocol [19]. Briefly, two single-band bandpass optical filters were used: $480 \mathrm{~nm}$ (D480/30x; Chroma, Bellows Falls, VT, USA) and 623 nm (FF01-623/24-25; Semrock, Brightline, Rochester, NY, USA). These filters were attached to an iPhone SE camera for image acquisition. The flash and high dynamic range options on the camera were disabled, and the camera editing filters were not applied. Quantification analysis of pigmentation was performed using ImageJ image processing software [26].

\subsection{Statistics}

Statistical analyses were performed using SPSS Statistics Software (Version 24; IBM Corp, Armonk, NY, USA). Data are expressed as the mean \pm SD. A one-way analysis of variance single factor followed by either a Tukey's honest significant difference or Games-Howell post hoc test were used to determine significant differences when applicable.

\section{Results and Discussion}

First, we synthesized a focused library of CFZ salts (hydrochloride, hydrobromide, hydrogen sulfate, nitrate, citrate, hydroiodide, hydrogen phosphate, acetate, and carbonate salts) and compared their fluorescence and Raman spectral properties. For fluorescence analysis, image data were acquired with the standard FITC and Cy5 excitation/emission channels of an epifluorescence microscope; for Raman spectral data, single crystals were analyzed and compared to spectra of isolated CLDIs (Figure 1). By visual inspection, CLDIs and CFZ-HCl exhibited almost identical fluorescence and Raman spectra, sharing the CLDIs signature peak at $1400 \mathrm{~cm}^{-1}$ (red line). CFZ-hydrobromide, CFZ-hydrogen sulfate, and CFZ-nitrate had similar Raman spectra when compared to CLDIs and $\mathrm{CFZ}-\mathrm{HCl}$; however, the $\mathrm{Cy} 5$ signal was much less prominent. Furthermore, based on CLDIs signature peak, the most prominent spectral peak of CFZ-hydrobromide, CFZ-hydrogen sulfate, and CFZ-nitrate showed a small shift in wavelength. All other CFZ salt crystals displayed a completely different Raman spectrum or possessed different visual/fluorescent profile compared to CLDIs. Thus, CFZ-HCl salt crystals most closely mimicked the optical properties of CLDIs.

To scale the synthesis of CFZ-HCl to multigram and larger quantities for manufacturing of a pharmaceutical-grade formulation for clinical trials, a new synthesis scheme was developed using hydrochloric acid for transforming clofazimine free base to hydrochloride salt crystals directly, without dissolving the free base in organic solvents. For free base particles of $\sim 100 \mu \mathrm{m}$ diameter or less, direct conversion hydrochloride crystals were complete by $72 \mathrm{~h}$, as determined using microscopy, ${ }^{1} \mathrm{H}-\mathrm{NMR}$, and Raman (Figure 2).

The protonation state of the CFZ molecule in the different CFZ crystal forms was examined via solution ${ }^{1} \mathrm{H}-\mathrm{NMR}$ studies, conducted in DMSO- $d_{6} \cdot{ }^{1} \mathrm{H}-\mathrm{NMR}$ data of newly synthesized CFZ-HCl crystals $\left(\mathrm{CFZ}-\mathrm{HCl}^{*}\right)$ depicts: ${ }^{1} \mathrm{H}$ NMR $\left(400 \mathrm{MHz}, \mathrm{DMSO}-d_{6}\right) \delta 9.29(\mathrm{~s}, 1 \mathrm{H}), 8.94(\mathrm{~s}, 1 \mathrm{H}), 8.26-8.17(\mathrm{~m}$, $1 \mathrm{H}), 8.04-7.95(\mathrm{~m}, 2 \mathrm{H}), 7.79(\mathrm{~m}, 4 \mathrm{H}), 7.60-7.53(\mathrm{~m}, 2 \mathrm{H}), 7.49-7.41(\mathrm{~m}, 2 \mathrm{H}), 7.37(\mathrm{~s}, 1 \mathrm{H}), 7.15-7.07(\mathrm{~m}, 1 \mathrm{H})$, $5.82(\mathrm{~s}, 1 \mathrm{H}), 3.68(\mathrm{dq}, J=6.5 \mathrm{~Hz}, 1 \mathrm{H}), 1.23(\mathrm{~d}, J=6.3 \mathrm{~Hz}, 6 \mathrm{H}) .{ }^{1} \mathrm{H}-\mathrm{NMR}$ data of control CFZ-HCl crystals depicts: ${ }^{1} \mathrm{H}$ NMR $\left(500 \mathrm{MHz}\right.$, DMSO- $\left.d_{6}\right) \delta 9.18(\mathrm{~s}, 1 \mathrm{H}), 8.86(\mathrm{~s}, 1 \mathrm{H}), 8.25-8.18(\mathrm{~m}, 1 \mathrm{H}), 8.05-7.95(\mathrm{~m}, 2 \mathrm{H})$, $7.79(\mathrm{~m}, 4 \mathrm{H}), 7.62-7.54(\mathrm{~m}, 2 \mathrm{H}), 7.49-7.42(\mathrm{~m}, 2 \mathrm{H}), 7.37(\mathrm{~s}, 1 \mathrm{H}), 7.16-7.08(\mathrm{~m}, 1 \mathrm{H}), 5.82(\mathrm{~s}, 1 \mathrm{H}), 3.68(\mathrm{dq}$, $J=6.5 \mathrm{~Hz}, 1 \mathrm{H}), 1.23(\mathrm{~d}, J=6.4 \mathrm{~Hz}, 6 \mathrm{H})$. Using our scalable synthesis method, the resulting CFZ-HCl${ }^{*}$ NMR spectra matched CFZ-HCl control spectra and was consistent with published spectra [16]. Both CFZ-HCl ${ }^{*}$ and control CFZ-HCl crystals revealed the expected protonation of the tertiary amine (Figure 2A) by having an extra singlet peak at 9.29 and $9.18 \mathrm{ppm}$, respectively (minor difference in chemical shift is attributed to the difference in the $\mathrm{pH}$ of the samples from different synthesis schemes). 
Furthermore, this protonation of the tertiary amine caused the chemical shift $(+\delta=0.05-0.60$ ppm $)$ for all other protons in CFZ- $\mathrm{HCl}^{*}$ to the same extent as in the control CFZ-HCl spectrum with respect to the CFZ free base spectrum, which confirmed the monoprotonated characteristic of the molecule (Figure 2C) [16]. Overall, the ${ }^{1} \mathrm{H}-\mathrm{NMR}$ spectrum of $\mathrm{CFZ}-\mathrm{HCl}^{*}$ and control CFZ-HCl crystals reflected identical protonation states of the molecule.

The chemical "fingerprint" of CFZ- $\mathrm{HCl}^{*}$ was further confirmed by Raman micro-spectroscopy due to the almost identical match of all of the peaks to $\mathrm{CFZ}-\mathrm{HCl}$ control spectra, including the signature peak at $1400 \mathrm{~cm}^{-1}$. Furthermore, the aqueous solubility of $\mathrm{CFZ}-\mathrm{HCl}^{*}$ matched the aqueous solubility of CFZ- $\mathrm{HCl}$ control crystals of approximately $18 \mu \mathrm{M}$ at $25{ }^{\circ} \mathrm{C}$ (data not shown) [22]. In conclusion, the final product was verified to have the same optical and fluorescence properties (Figure 2B), as well as the same chemical characteristics, according to ${ }^{1} \mathrm{H}-\mathrm{NMR}$ and Raman micro-spectroscopy, as the reference, pure CFZ-HCl salt crystals, synthesized using the established method [16,19] (Figure 2C,D).

To formulate micronized $\mathrm{CFZ}-\mathrm{HCl}$ salt crystals and characterize the extent to which they mimicked CLDIs, ${ }^{1} \mathrm{H}-\mathrm{NMR}$, single crystal Raman micro-spectroscopy, and $\mathrm{pXRD}$ were used for comparative analysis. Following micronization and sterilization of bulk $\mathrm{CFZ}-\mathrm{HCl}$, chemical and structural characteristics of $\mathrm{CFZ}-\mathrm{HCl}$ salt crystals remained relatively unchanged (Figure $3 \mathrm{~A}-\mathrm{C}$ ). ${ }^{1} \mathrm{H}-\mathrm{NMR}$ spectral (Figure 3A) and single crystal Raman micro-spectroscopy peaks (Figure 3B) were preserved with almost identical match, indicating that the chemical structure of CFZ-HCl crystals was not altered by micronization or sterilization. Furthermore, pXRD spectra revealed that the majority of diffraction peaks were preserved as well, including the $\mathrm{CFZ}-\mathrm{HCl}$ signature peak at $2 \theta=7.2^{\circ}$ that is absent in $\mathrm{CFZ}$ free base, indicating the preservation of the crystal structure (Figure 3C) [16].

Following dispersion of individual drug crystals in IV diluent buffer, Raman spectral analysis quantitatively confirmed that the CFZ-HCl particles from the micronized, sterilized powder, had the same properties (Table 1).

Table 1. Quality and stability of single CFZ-HCl and CFZ free base micronized drug crystals measured by single crystal Raman micro-spectroscopy.

\begin{tabular}{lllll}
\hline Sample $(\boldsymbol{n}=\mathbf{3})$ & $\begin{array}{l}\text { \# Drug Crystals } \\
\text { Scanned }\end{array}$ & $\begin{array}{l}\text { \# CFZ-HCl } \\
\text { Crystals }\end{array}$ & $\begin{array}{l}\text { \# CFZ Free } \\
\text { Base Crystals }\end{array}$ & \# Other Particles \\
\hline Micronized CFZ-HCl & 100 & $98 \pm 1$ & 0 & $2 \pm 1$ \\
Micronized CFZ-HCl in Diluent * & 100 & $98 \pm 1$ & 0 & $2 \pm 1$ \\
Micronized CFZ Free Base & 100 & 0 & $97 \pm 1$ & $3 \pm 1$ \\
\hline
\end{tabular}

* Diluent in IV injectable formulation for in vivo studies.
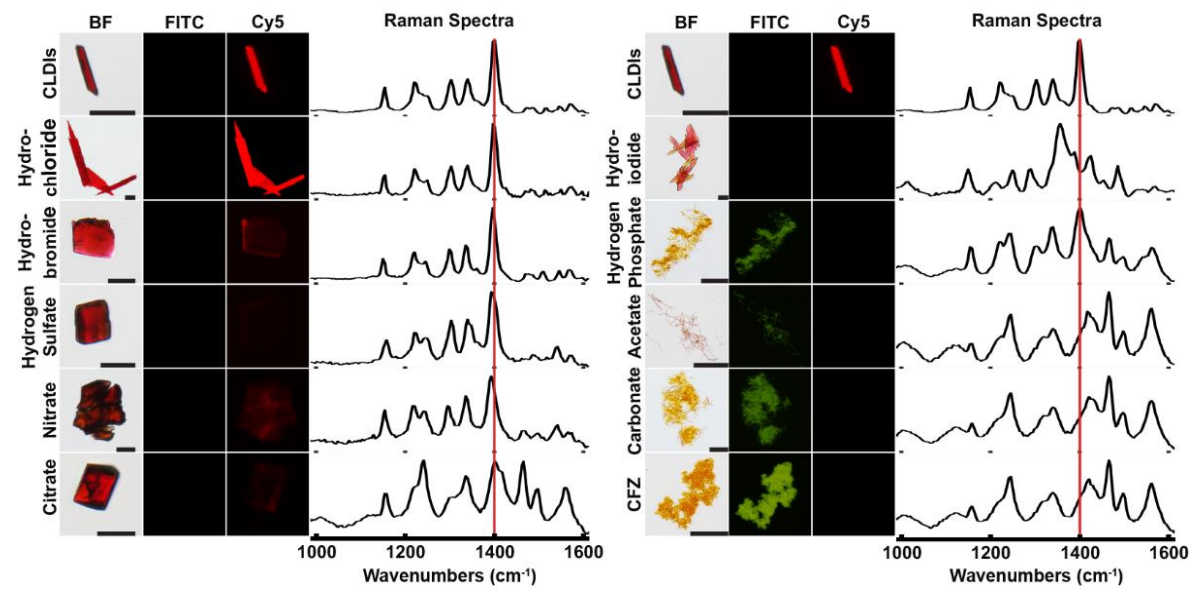

Figure 1. Single crystal Raman micro-spectroscopy spectra and brightfield (BF)/fluorescent (FITC, Cy5) microscopy images of various synthesized clofazimine (CFZ) salts compared to crystal-like drug inclusions (CLDIs) and CFZ free base. The red line represents the signature peak of CLDIs at $1400 \mathrm{~cm}^{-1}$. Scale bar $=20 \mu \mathrm{m}$. 
A<smiles></smiles>

B

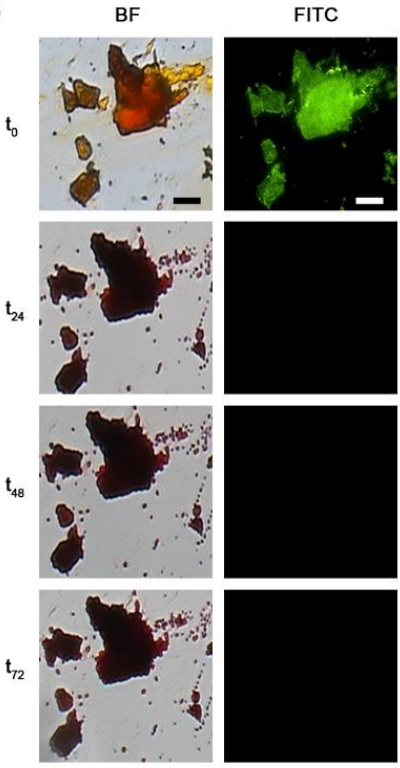

CFZ-HCI<smiles>CC(C)N=c1cc2n(-c3ccc(Cl)cc3)c3ccccc3nc-2cc1Nc1ccc(Cl)cc1</smiles>

C
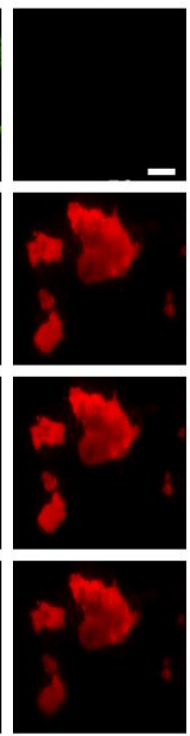
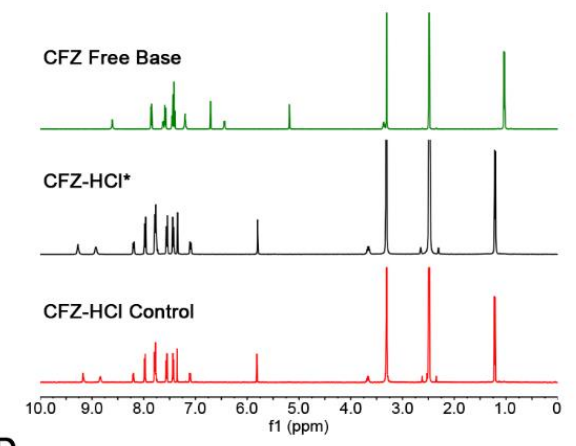

D

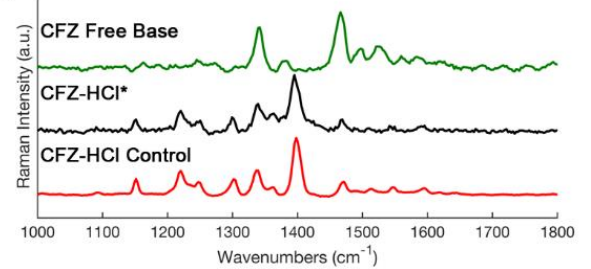

Figure 2. Chemical structures of CFZ free base and CFZ-HCl (A). Brightfield (BF)/fluorescent (FITC, Cy5) microscopy images (B); ${ }^{1} \mathrm{H}-\mathrm{NMR}(\mathbf{C})$, and Raman micro-spectroscopy spectra (D) of synthesized $\mathrm{CFZ}-\mathrm{HCl}$ salt crystals via new synthesis scheme $\left({ }^{*}\right)$ compared to the established CFZ-HCl salt crystals and CFZ free base. Scale bar $=50 \mu \mathrm{m}$.
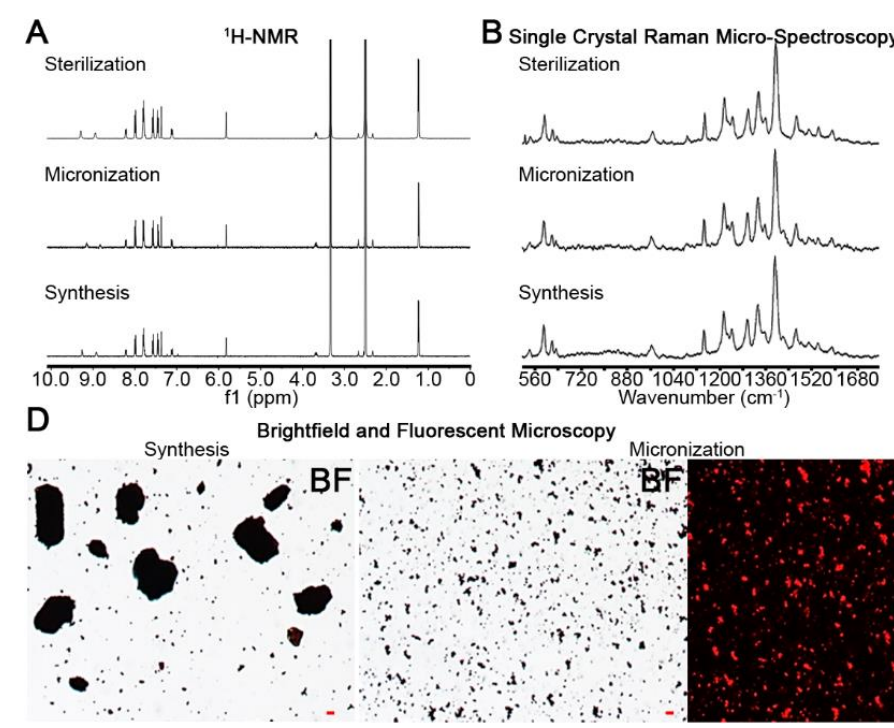

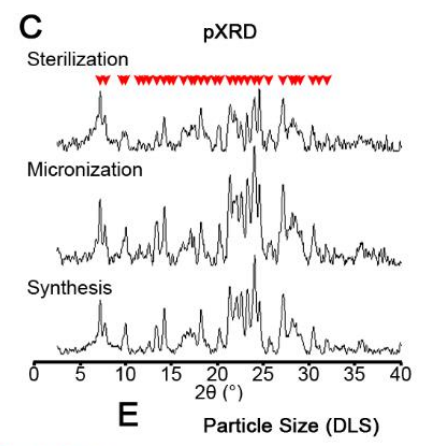

E

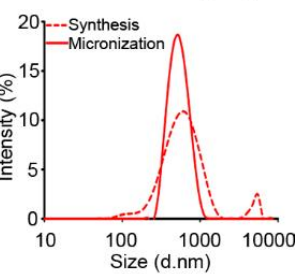

Figure 3. The integrity of the salt crystals was maintained throughout the manufacturing process (synthesis, micronization, and sterilization) of a biomimetic formulation of micronized CFZ-HCl salt crystals. This is evidenced by the spectra from ${ }^{1} \mathrm{H}-\mathrm{NMR}$ (A); single crystal Raman micro-spectroscopy (B); and powder X-ray diffraction (pXRD) (C). The red arrows in pXRD spectrum (C) indicate the peaks that are preserved after micronization and sterilization. The efficacy of micronization is depicted in brightfield and fluorescent images (D) and particle size distribution (E). Scale bar $=5 \mu \mathrm{m}$. 
In IV diluent buffer, the micronized, sterilized microparticles were completely dispersed. Ultimately, the size and the dispersion of the particles can be adjusted by varying the concentration of the detergent present in the diluent (e.g., polysorbate 80); the higher the concentration, the smaller and more dispersed the particles are (data not shown). In this case, the IV injection, the maximum concentration of polysorbate 80 was used $(0.5 \%)$ to make the particles as small and as dispersed as possible [24]. As a result, the microcrystals exhibited the expected Cy5 and FITC fluorescence of $\mathrm{CFZ}-\mathrm{HCl}$ and were homogeneous in size distribution (Figure 3D). By utilizing dynamic light scattering analysis (Figure 3E), there was one narrow particle distribution of $547 \pm 160 \mathrm{~nm}$, an ideal size for parenteral formulations. In contrast, prior to micronization, the starting material exhibited 2 major wide particle size distributions of $621 \pm 300 \mathrm{~nm}$ and $5035 \pm 592 \mathrm{~nm}$, respectively (Figure 3E). Thus, air jet milling produced a stable micronized product that could be readily sterilized, preserving a desirable size distribution.

Following physical characterization, the sterilized CFZ-HCl microcrystals were tested for stability properties, by comparing fluorescence in the IV diluent, synthetic lysosomal buffer [19], and physiological saline media (PBS) (Figure 4). The micronized particles were stable in diluent (pH 5) and synthetic lysosomal buffer ( $\mathrm{pH} 4.5)$ as evidenced by the preservation of a strong fluorescence signal in the Cy5 channel (indicative of CFZ-HCl salt) and absence of fluorescence in the FITC channel (indicative of CFZ free base) (Figure 4). In PBS (pH 7.6), the CFZ-HCl microcrystals were unstable as evidenced by the increased fluorescence in the FITC channel and decreased fluorescence in the Cy5 channel, consistent with the conversion of CFZ-HCl to CFZ free base (Figure 4). Based on these results, we inferred that the diluent would be appropriate for in vivo injection and that the particles may be stabilized by macrophages following phagocytosis.

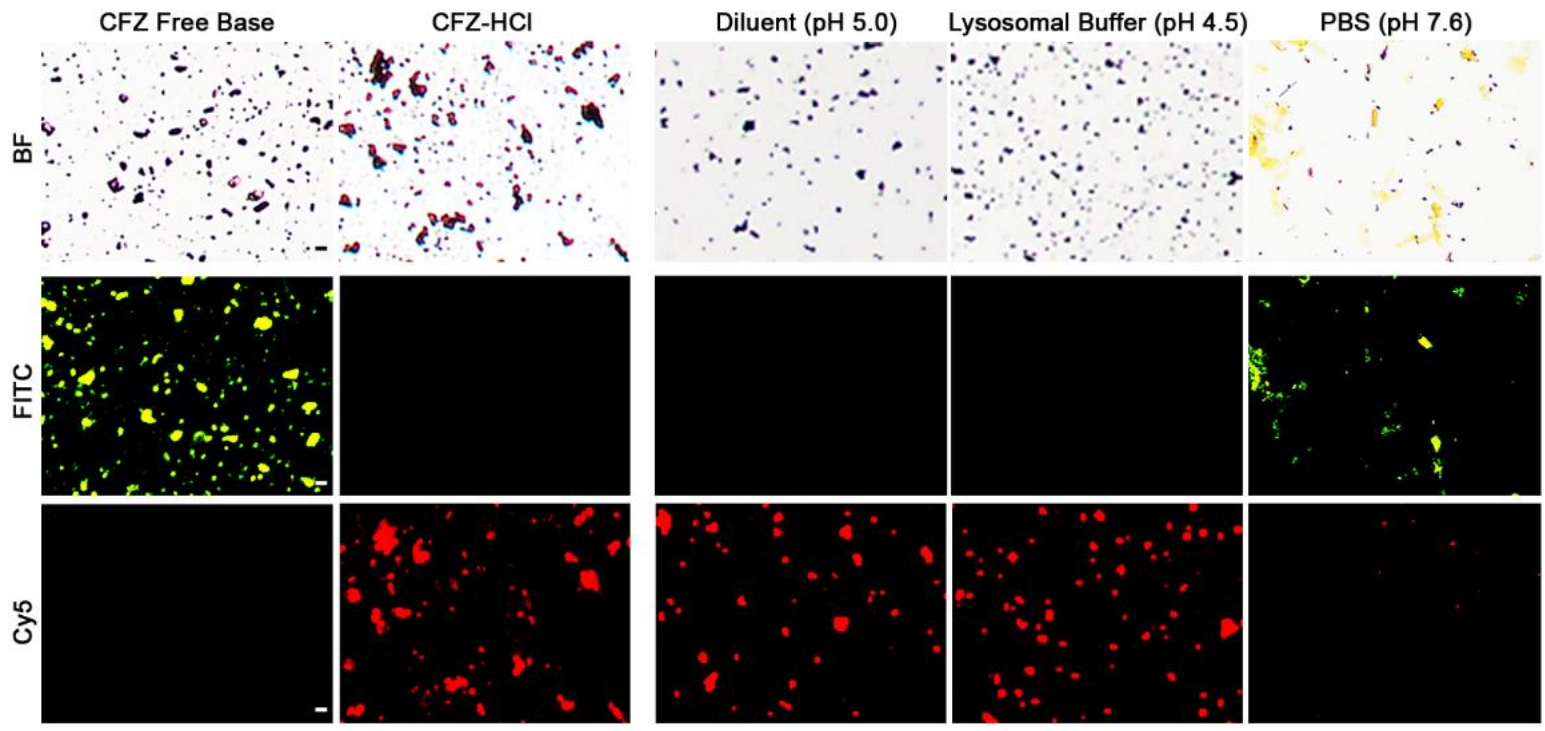

Figure 4. In vitro stability of the biomimetic formulation of micronized CFZ-HCl salt crystals in IV diluent, synthetic lysosomal buffer, and PBS after $24 \mathrm{~h}$ utilizing brightfield and fluorescent (FITC, Cy5) microscopy. Scale bar $=5 \mu \mathrm{m}$.

To confirm this, RAW 264.7 macrophages were incubated with isolated CLDIs and micronized CFZ-HCl. The stability of the phagocytosed drug particles in live cells was microscopically evaluated following ingestion, by visual inspection (Figure 5A). RAW macrophages internalized and stabilized CLDIs as well as CFZ-HCl microcrystals, based on the strong Cy5 fluorescence signal and the absence of a FITC fluorescence signal observed in macrophages during the course of a 48-h incubation period (Figure 5A). As a control for these experiments, macrophages were incubated with CFZ free base microcrystals which fluoresce in the FITC channel, but not in the Cy5 channel. Interestingly, brightfield and fluorescent images showed that the CFZ free base gradually lost their FITC fluorescence and 
gained the Cy5 fluorescence, suggesting that the macrophages can transform the free base to the protonated salt form of the drug (Figure 5A).

Most importantly, incubation with CFZ-HCl was not cytotoxic. In fact, cell viability was constant ( $\sim 90-100 \%)$ throughout the $48 \mathrm{~h}$ incubation regardless of the treatment (Figure $5 \mathrm{~B}$ ). These results were further validated by the fact that the biomimetic formulation of $\mathrm{CFZ}-\mathrm{HCl}$ microcrystals were phagocytosed and stabilized by macrophages, mimicking CLDIs, which led us to conclude that these drug microcrystals would also be prone to phagocytosis and stabilization by resident tissue macrophages in vivo.

A

CLDI

CFZ-HCl
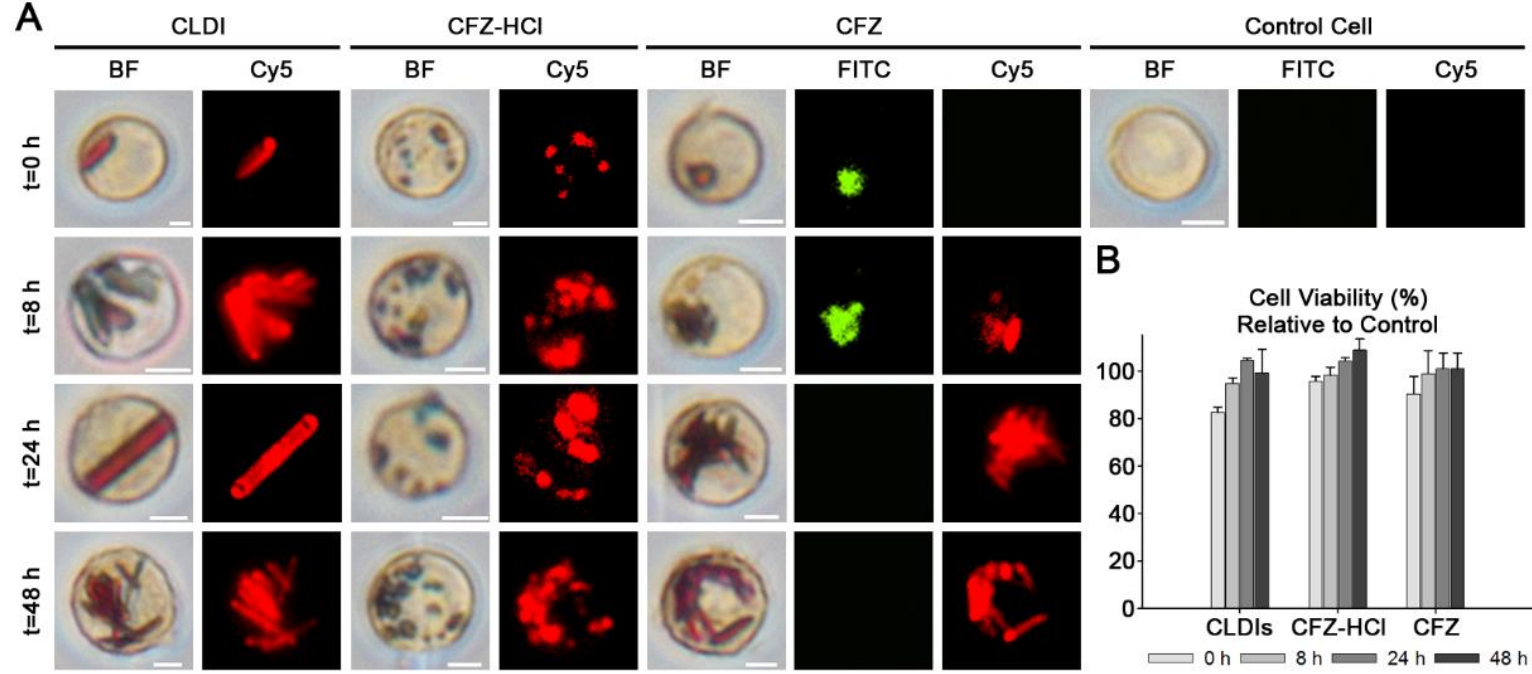

B

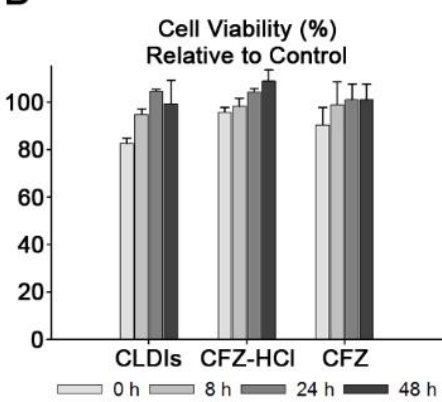

Figure 5. In vitro stability of the micronized CFZ-HCl salt and CFZ free base drug crystals in RAW 264.7 murine macrophages over $48 \mathrm{~h}$ compared to CLDIs, is depicted via brightfield and fluorescent images (FITC, Cy5) (A). Cell viability was not altered by 8,24 , and $48 \mathrm{~h}$ of treatment with CLDIs, CFZ-HCl, or CFZ free base (B).

In vivo studies were performed to assess the effect of injected CFZ-HCl on the spectral reflectance properties of the skin and also to determine whether the particles accumulate in macrophages of the different organs as reported in mice fed with oral CFZ (i.e., spleen and liver) $[13-15,19]$. Since this analysis was primarily focused on assessing the extent of skin pigmentation, the IV dose $(200 \mathrm{mg} / \mathrm{kg}$ ), which translates to an approximate total dose of $6 \mathrm{mg}$ of CFZ-HCl microcrystals (assuming 100\% bioavailability) was specifically chosen to be equivalent to the amount of orally administered CFZ (total of $\sim 6 \mathrm{mg}$, based on a bioavailability of $10 \mathrm{mg} / \mathrm{kg} / \mathrm{d}$ ) $[3,13,19,21]$ under which the maximum CFZ-induced skin pigmentation occurs when CFZ is administered orally ( $\sim 3$ weeks of oral administration) [19].

All mice ( $n=5$ out of 5 ) that were injected with the CFZ-HCl microcrystal formulation survived the injection (100\% survival) and did not show any signs of toxicity. Analyzing the distribution patterns of $\mathrm{CFZ}-\mathrm{HCl}$ microcrystals in these animals, $\mathrm{Cy} 5$ fluorescence was observed in liver and spleen, form naturally in CFZ-fed mice (Figure 6).

In regards to the major side effect of oral CFZ therapy, the impact of the injected microparticles on skin pigmentation was quantitatively determined using a spectral reflectance assay as previously established [19]. Based on the skin reflectance signal acquired at the $480 \mathrm{~nm}$ and $623 \mathrm{~nm}$ optical filters, IV CFZ-HCl injected mice did not result in detected skin pigmentation $(480 \mathrm{~nm}$, no significant difference versus untreated mice, analysis of variance single factor, $n=4)$. Both untreated and IV injected mice exhibited significantly lower pigmentation than 9 week orally fed CFZ mice, with the $480 \mathrm{~nm}$ wavelength filter $(p<0.05$, analysis of variance single factor, Games-Howell, $n=4)$ (Figure 7A,B). Importantly, the skin pigmentation of orally-fed mice is maximal at 3 weeks and then declines with continued feeding [19]; therefore, we can infer that IV injected mice are also less pigmented than 
mice fed with CFZ for 3 weeks. Additionally, the $623 \mathrm{~nm}$ optical filter (indicative of the presence of $\mathrm{CFZ}-\mathrm{HCl}$ ) was also unable to detect any significant skin pigmentation that may have arisen from partitioning of circulating CFZ-HCl particles from blood to skin [19]. Of noteworthy significance, the lack of skin pigmentation observed in the $\mathrm{CFZ}-\mathrm{HCl}$ injected mice cannot be explained by an overt toxicological effect of the drug leading to decreased mice viability, as all mice survived the injection without obvious toxicological consequences. As a caveat, it is important to note that the extent of skin pigmentation is not necessarily a direct reflection of CFZ accumulation in the skin, since the spectral reflectance properties of the skin can also be impacted by the amount of CFZ that circulates through the skin capillaries, as well as the optical (absorbance) properties of the CFZ molecules which can change depending on the molecules' ionization, aggregation, and redox states. Ultimately, the advantages of parenteral versus oral CFZ remain to be conclusively established under conditions leading to therapeutic efficacy, which will depend on the treatment regimen and clinical indication.

To further probe for the presence of toxic side effects resulting from the injected microparticles, $\mathrm{TNF} \alpha$, IL-1RA, and interleukin-1 beta (IL-1 $\beta$ ) were measured. TNF $\alpha$ and IL-1 $\beta$ are pro-inflammatory cytokines that are released by cells, primarily macrophages, in response to inflammatory stimuli. IL-1RA is an early-acting acute-phase anti-inflammatory cytokine that dampens a broad spectrum of inflammatory conditions by inhibiting the activity of IL-1 $\beta$, an important mediator of the inflammatory response $[3,20]$. However, none of these cytokines were significantly altered by an IV injection of CFZ-HCl (Figure 7C). In fact, IL-1RA levels were similar between treated and untreated groups ( $p<0.05$, analysis of variance single factor, Games-Howell, $n=5$ (both CFZ groups), $n=4$ (Control group); Figure $7 \mathrm{C}$ ), while the plasma IL- $1 \beta$ and TNF $\alpha$ concentrations were below the limit of detection $(\mathrm{IL}-1 \beta \mathrm{LOD}=12.5 \mathrm{pg} / \mathrm{mL} ; \mathrm{TNF} \alpha \mathrm{LOD}=10.9 \mathrm{pg} / \mathrm{mL})$.
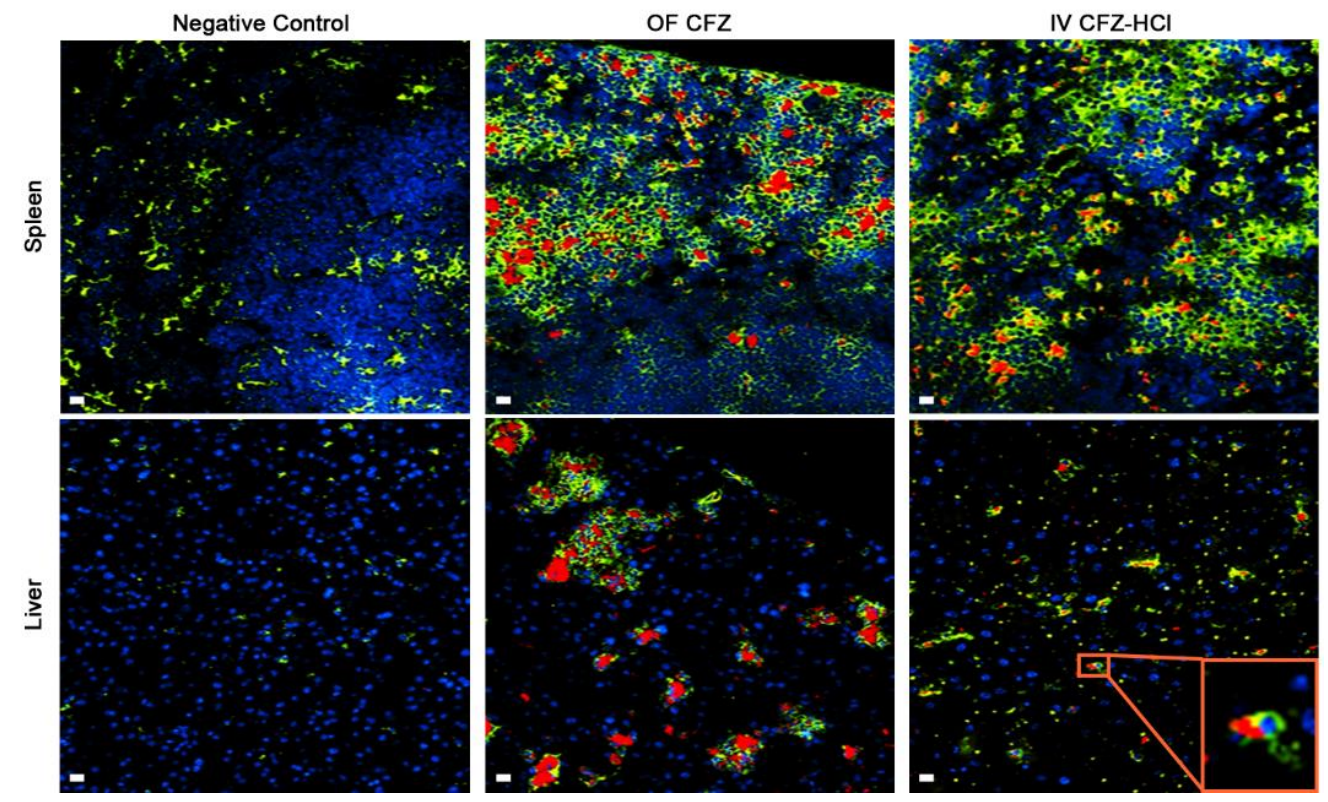

Figure 6. In vivo stability and phagocytosis of the biomimetic formulation of micronized CFZ-HCl salt crystals following IV injection to mice compared to 9 weeks orally fed (OF) CFZ mice. Images represent CD68 immunohistochemistry of cryo-sections of spleen and liver from OF CFZ and untreated (negative control) mice. Blue (DAPI)—nucleus; green (FITC)—CD68(+) macrophages; red (Cy5)—CLDIs/CFZ-HCl microcrystals. Scale bar $=20 \mu \mathrm{m}$. 
A

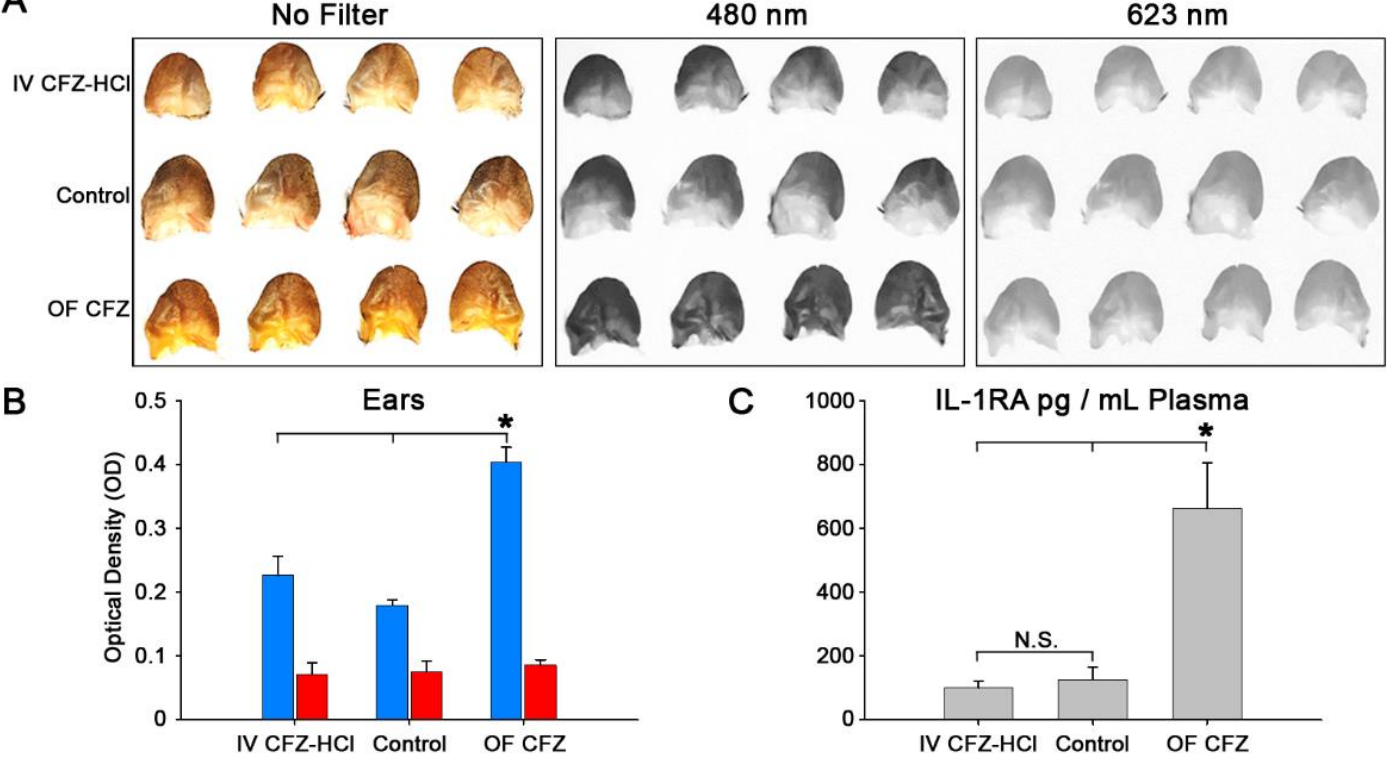

Figure 7. Quantitative analysis of skin pigmentation and plasma IL-1RA concentrations following IV administration of CFZ-HCl (IV CFZ-HCl) and oral administration of CFZ (9 week OF CFZ) compared to untreated mice (control). Images of mouse ears from treatment groups and the extent of their reflectance using $480 \mathrm{~nm}$ and $623 \mathrm{~nm}$ optical filters (A). Quantitative analysis of the pigmentation of mouse ears from CFZ treated mice compared to untreated mice $(n=4)$ via reflectance spectroscopy (blue $=480 \mathrm{~nm}$; red $=623 \mathrm{~nm}$ filter; ${ }^{*} p<0.05$, analysis of variance (ANOVA) single factor, Games-Howell) (B). Plasma concentrations of IL-1RA in CFZ treated mice compared to untreated mice ( $n=5$ (CFZ groups); $n=4$ (untreated group)) ${ }^{*} p<0.05$, analysis of variance (ANOVA) single factor, Games-Howell) (C).

\section{Conclusions}

In conclusion, a biocompatible, biomimetic formulation of CFZ-HCl microcrystals proved suitable for parenteral, systemic administration, while avoiding the skin pigmentation and immunological response that accompanies oral CFZ administration. Based on our in vitro and in vivo data, micronized $\mathrm{CFZ}-\mathrm{HCl}$ crystals were ingested by tissue macrophages and accumulated in liver and spleen, similar to CLDIs; yet, no skin pigmentation was evident, unlike oral administration of CFZ. IV administration did not result in overt toxicity and did not induce measurable changes in acute inflammatory response biomarkers. The anti-inflammatory cytokine, IL-1RA, which we have previously shown to be elevated following oral administration of CFZ $[3,20]$, was not changed by the injected CFZ-HCl microparticles. Our findings support additional studies into the possible use of parenteral CFZ- $\mathrm{HCl}$ as a means to circumvent the skin pigmentation side effect of the oral drug. For example, an inhalable, aerosolized formulation of CFZ-HCl may be a good strategy for treating MDR-TB. Previously, Brunaugh et al. [27] and Verma et al. [28] investigated the feasibility of inhalable micronized CFZ free base microparticles against MDR-TB. Nevertheless, based on a more straightforward synthesis route, scalable manufacturing, and other practical considerations, an inhalable formulation of CFZ-HCl microcrystals could offer a more viable approach for pharmaceutical product development. As a wise man once said: "the most fruitful basis for the discovery of a new drug is to start with an old drug [29-31]".

\section{Patents}

Design and Composition of Cell-Stabilized Pharmaceutical Formulations. G.R. Rosania, P.J.A. Kenis, E.M. Horstman, T. Woldemichael, M.D. Murashov, P. Rzeczycki, R.K. Keswani, T.A. Arenson. 3 May 2018. Pub. No. WO/2018/081072. International Application No. PCT/US2017/058017 
Author Contributions: Conceptualization, M.D.M.; Data curation, M.D.M. and J.D.-E.; Formal analysis, M.D.M.; Funding acquisition, X.W., K.A.S. and G.R.R.; Investigation, M.D.M.; Methodology, M.D.M., J.D.-E., V.L., J.W.Y.T. and R.L.; Project administration, K.A.S. and G.R.R.; Supervision, M.D.M. and G.R.R.; Validation, M.D.M., J.D.-E. and V.L.; Visualization, M.D.M.; Writing—original draft, M.D.M.; Writing—review \& editing, M.D.M., J.D.-E., V.L., J.W.Y.T., R.L., X.W., K.A.S. and G.R.R.

Funding: This research was funded by the University of Michigan (MCubed, College of Pharmacy Upjohn Award, and MEDC Mi-TRAC (Kickstart) Award) and grants from the National Institutes of Health (NIH) (R01 GM078200; R01 GM111400; and P50 CA186786). The content is solely the responsibility of the authors and does not necessarily represent the official views of the National Institute of General Medical Sciences (NIGMS), National Cancer Institute (NCI), or the NIH.

Acknowledgments: The authors are thankful to the University of Michigan's Biochemical NMR Core Laboratory.

Conflicts of Interest: The authors declare no conflict of interest. Gus R. Rosania is consulting for Bristol-Myers Squibb. The funders had no role in the design of the study; in the collection, analyses, or interpretation of data; in the writing of the manuscript, and in the decision to publish the results.

\section{References}

1. Cholo, M.C.; Steel, H.C.; Fourie, P.B.; Germishuizen, W.A.; Anderson, R. Clofazimine: Current status and future prospects. J. Antimicrob. Chemother. 2012, 67, 290-298. [CrossRef] [PubMed]

2. Barry, V.C.; Belton, J.G.; Conalty, M.L.; Denneny, J.M.; Edward, D.W.; O’Sullivan, J.F.; Twomey, D.; Winder, F. A new series of phenazines (rimino-compounds) with high antituberculosis activity. Nature 1957, 179, 1013-1015. [CrossRef] [PubMed]

3. Yoon, G.S.; Keswani, R.K.; Sud, S.; Rzeczycki, P.M.; Murashov, M.D.; Koehn, T.A.; Standiford, T.J.; Stringer, K.A.; Rosania, G.R. Clofazimine Biocrystal Accumulation in Macrophages Upregulates Interleukin 1 Receptor Antagonist Production to Induce a Systemic Anti-Inflammatory State. Antimicrob. Agents Chemother. 2016, 60, 3470-3479. [CrossRef] [PubMed]

4. World Health Organization Leprosy Report. Available online: http://www.who.int/mediacentre/ factsheets/fs101/en (accessed on 26 October 2018).

5. Arbiser, J.L.; Moschella, S.L. Clofazimine: A review of its medical uses and mechanisms of action. J. Am. Acad. Dermatol. 1995, 32, 241-247. [CrossRef]

6. Tyagi, S.; Ammerman, N.C.; Li, S.Y.; Adamson, J.; Converse, P.J.; Swanson, R.V.; Almeida, D.V.; Grosset, J.H. Clofazimine shortens the duration of the first-line treatment regimen for experimental chemotherapy of tuberculosis. Proc. Natl. Acad. Sci. USA 2015, 112, 869-874. [CrossRef] [PubMed]

7. Lechartier, B.; Cole, S.T. Mode of Action of Clofazimine and Combination Therapy with Benzothiazinones against Mycobacterium tuberculosis. Antimicrob. Agents Chemother. 2015, 59, 4457-4463. [CrossRef] [PubMed]

8. Williams, K.; Minkowski, A.; Amoabeng, O.; Peloquin, C.A.; Taylor, D.; Andries, K.; Wallis, R.S.; Mdluli, K.E.; Nuermberger, E.L. Sterilizing activities of novel combinations lacking first- and second-line drugs in a murine model of tuberculosis. Antimicrob. Agents Chemother. 2012, 56, 3114-3120. [CrossRef] [PubMed]

9. Dooley, K.E.; Obuku, E.A.; Durakovic, N.; Belitsky, V.; Mitnick, C.; Nuermberger, E.L.; Efficacy Subgroup, R.-T. World Health Organization group 5 drugs for the treatment of drug-resistant tuberculosis: Unclear efficacy or untapped potential? J. Infect. Dis. 2013, 207, 1352-1358. [CrossRef] [PubMed]

10. Gopal, M.; Padayatchi, N.; Metcalfe, J.Z.; O'Donnell, M.R. Systematic review of clofazimine for the treatment of drug-resistant tuberculosis. Int. J. Tuberc. Lung Dis. 2013, 17, 1001-1007. [CrossRef] [PubMed]

11. Sukpanichnant, S.; Hargrove, N.S.; Kachintorn, U.; Manatsathit, S.; Chanchairujira, T.; Siritanaratkul, N.; Akaraviputh, T.; Thakerngpol, K. Clofazimine-induced crystal-storing histiocytosis producing chronic abdominal pain in a leprosy patient. Am. J. Surg. Pathol. 2000, 24, 129-135. [CrossRef] [PubMed]

12. Belaube, P.; Devaux, J.; Pizzi, M.; Boutboul, R.; Privat, Y. Small bowel deposition of crystals associated with the use of clofazimine (Lamprene) in the treatment of prurigo nodularis. Int. J. Lepr. Other Mycobact. Dis. 1983, 51, 328-330. [PubMed]

13. Baik, J.; Stringer, K.A.; Mane, G.; Rosania, G.R. Multiscale distribution and bioaccumulation analysis of clofazimine reveals a massive immune system-mediated xenobiotic sequestration response. Antimicrob. Agents Chemother. 2013, 57, 1218-1230. [CrossRef] [PubMed]

14. Baik, J.; Rosania, G.R. Macrophages sequester clofazimine in an intracellular liquid crystal-like supramolecular organization. PLoS ONE 2012, 7, e47494. [CrossRef] [PubMed] 
15. Baik, J.; Rosania, G.R. Molecular imaging of intracellular drug-membrane aggregate formation. Mol. Pharm. 2011, 8, 1742-1749. [CrossRef] [PubMed]

16. Keswani, R.K.; Baik, J.; Yeomans, L.; Hitzman, C.; Johnson, A.M.; Pawate, A.S.; Kenis, P.J.; RodriguezHornedo, N.; Stringer, K.A.; Rosania, G.R. Chemical Analysis of Drug Biocrystals: A Role for Counterion Transport Pathways in Intracellular Drug Disposition. Mol. Pharm. 2015, 12, 2528-2536. [CrossRef] [PubMed]

17. Maia, M.V.; Cunha Mda, G.; Cunha, C.S. Adverse effects of alternative therapy (minocycline, ofloxacin, and clofazimine) in multibacillary leprosy patients in a recognized health care unit in Manaus, Amazonas, Brazil. An. Bras. Dermatol. 2013, 88, 205-210. [CrossRef] [PubMed]

18. Tang, S.; Yao, L.; Hao, X.; Liu, Y.; Zeng, L.; Liu, G.; Li, M.; Li, F.; Wu, M.; Zhu, Y.; et al. Clofazimine for the treatment of multidrug-resistant tuberculosis: Prospective, multicenter, randomized controlled study in China. Clin. Infect. Dis. 2015, 60, 1361-1367. [PubMed]

19. Murashov, M.D.; LaLone, V.; Rzeczycki, P.M.; Keswani, R.K.; Yoon, G.S.; Sud, S.; Rajeswaran, W.; Larsen, S.; Stringer, K.A.; Rosania, G.R. The Physicochemical Basis of Clofazimine-Induced Skin Pigmentation. J. Investig. Dermatol. 2017, 138, 697-703. [CrossRef] [PubMed]

20. Yoon, G.S.; Sud, S.; Keswani, R.K.; Baik, J.; Standiford, T.J.; Stringer, K.A.; Rosania, G.R. Phagocytosed Clofazimine Biocrystals Can Modulate Innate Immune Signaling by Inhibiting TNFalpha and Boosting IL-1RA Secretion. Mol. Pharm. 2015, 12, 2517-2527. [CrossRef] [PubMed]

21. Keswani, R.K.; Yoon, G.S.; Sud, S.; Stringer, K.A.; Rosania, G.R. A far-red fluorescent probe for flow cytometry and image-based functional studies of xenobiotic sequestering macrophages. Cytom. Part A 2015, 87, 855-867. [CrossRef] [PubMed]

22. Woldemichael, T.; Keswani, R.K.; Rzeczycki, P.M.; Murashov, M.D.; LaLone, V.; Gregorka, B.; Swanson, J.A.; Stringer, K.A.; Rosania, G.R. Reverse Engineering the Intracellular Self-Assembly of a Functional Mechanopharmaceutical Device. Sci. Rep. 2018, 8, 2934. [CrossRef] [PubMed]

23. Rzeczycki, P.; Yoon, G.S.; Keswani, R.K.; Sud, S.; Stringer, K.A.; Rosania, G.R. Detecting ordered small molecule drug aggregates in live macrophages: A multi-parameter microscope image data acquisition and analysis strategy. Biomed. Opt. Express 2017, 8, 860-872. [CrossRef] [PubMed]

24. U.S. Food \& Drug Administration. Inactive Ingredient Search for Approved Drug Products. Available online: https:/ / www.accessdata.fda.gov/scripts/cder/iig/index.cfm (accessed on 26 October 2018).

25. Trexel, J.; Yoon, G.S.; Keswani, R.K.; McHugh, C.; Yeomans, L.; Vitvitsky, V.; Banerjee, R.; Sud, S.; Sun, Y.; Rosania, G.R.; et al. Macrophage-Mediated Clofazimine Sequestration Is Accompanied by a Shift in Host Energy Metabolism. J. Pharm. Sci. 2017, 106, 1162-1174. [CrossRef] [PubMed]

26. Schneider, C.A.; Rasband, W.S.; Eliceiri, K.W. NIH Image to ImageJ: 25 years of image analysis. Nat. Methods 2012, 9, 671-675. [CrossRef] [PubMed]

27. Brunaugh, A.D.; Jan, S.U.; Ferrati, S.; Smyth, H.D. Excipient-Free Pulmonary Delivery and Macrophage Targeting of Clofazimine via Air Jet Micronization. Mol. Pharm. 2017, 14, 4019-4031. [CrossRef] [PubMed]

28. Verma, R.K.; Germishuizen, W.A.; Motheo, M.P.; Agrawal, A.K.; Singh, A.K.; Mohan, M.; Gupta, P.; Datta Gupta, U.; Cholo, M.; Anderson, R.; et al. Inhaled microparticles containing clofazimine are efficacious in treatment of experimental tuberculosis in mice. Antimicrob. Agents Chemother. 2013, 57, 1050-1052. [CrossRef] [PubMed]

29. Chong, C.R.; Sullivan, D.J., Jr. New uses for old drugs. Nature 2007, 448, 645-646. [CrossRef] [PubMed]

30. Chen, H.; Wu, J.; Gao, Y.; Chen, H.; Zhou, J. Scaffold Repurposing of Old Drugs Towards New Cancer Drug Discovery. Curr. Top. Med. Chem. 2016, 16, 2107-2114. [CrossRef] [PubMed]

31. Yella, J.K.; Yaddanapudi, S.; Wang, Y.; Jegga, A.G. Changing Trends in Computational Drug Repositioning. Pharmaceuticals 2018, 11, 57. [CrossRef] [PubMed]

(C) 2018 by the authors. Licensee MDPI, Basel, Switzerland. This article is an open access article distributed under the terms and conditions of the Creative Commons Attribution (CC BY) license (http:/ / creativecommons.org/licenses/by/4.0/). 